\title{
Long-term prognosis of children with ulcerative colitis
}

\author{
K. M. GOEL and ROBERT A. SHANKS \\ From the Royal Hospital for Sick Children, Glasgow
}

\begin{abstract}
Goel, K. M., and Shanks, R. A. (1973). Archives of Disease in Childhood, 48, 337. Long-term prognosis of children with ulcerative colitis. The subsequent course of ulcerative colitis in 25 children admitted to hospital during the period 1931 to 1971 is reviewed.

The period of observation averaged 24 years, ranging from 1 to 41 years. 19 patients showed extracolonic manifestations. 4 patients had a single attack of colitis, and in 19 the disease was of the chronic intermittent type. There was one case each of the acute fulminating and chronic continuous types.

Three of 8 patients who had colectomy died postoperatively. One further patient died later of carcinoma of the rectal stump.

At follow-up 5 patients $(20 \%)$ had died and the remaining $20(80 \%)$ were in remission.

Although the case for surgery in the treatment of acute fulminating or resistant ulcerative colitis may be clear, that for prophylactic panproctocolectomy while the disease is in remission requires further study.
\end{abstract}

Surgery in the treatment of ulcerative colitis which fails to respond to more conservative measures is a well-known, though hazardous, procedure. Surgery as a prophylactic measure against later carcinoma is perhaps less well established. A recent review of life expectancy in children with ulcerative colitis recommends prophylactic panproctocolectomy because of the increasing risk of carcinoma, even in those in whom the disease is quiescent (Devroede et al., 1971); but it is significant that the authors make the proviso that such surgical treatment cannot be advised without qualification. This emphasizes the dilemma in which those who treat children with ulcerative colitis find themselves, for who would not shrink from a treatment so irrevocable and so socially disabling? It seemed reasonable, therefore, to try once more to assess the course and long-term prognosis of this disease when it begins in childhood. The purpose of this paper is to report a follow-up study of all cases of ulcerative colitis admitted to this hospital in the past $\mathbf{4 1}$ years. The last review in Britain of ulcerative colitis in childhood was in 1960 (Platt, Schlesinger, and Benson, 1960).

Ulcerative colitis is a nonspecific inflammatory disease of the large intestine which in children is basically the same disease as in adults. In childhood, however, there is, in addition, a profound

Received 29 August 1972. disturbance of growth, development, and sexual maturation. There is also said to be a greater likelihood of carcinomatous change, as the incidence of carcinoma is believed to be related to the duration of the disease. The clinical picture may be acute fulminating, chronic continuous, chronic intermittent, or there may be a single attack with subsequent freedom from symptoms. It appears that the disease is less common in children than in adults (Hanley and Ray, 1968).

\section{Material and methods}

From February 1931 to February 1972 a total of 25 children with ulcerative colitis was admitted to this hospital. The diagnosis was considered acceptable for the present study if the symptoms were compatible and if proctosigmoidoscopy or radiological examination of the bowel (usually both) supported the diagnosis. All had bloody diarrhoea and all were sigmoidoscoped: 23 showed the typical ulceration of ulcerative colitis, the other 2 showed contact bleeding, the diagnosis being confirmed by biopsy. In 20 the barium enema showed lack of haustration with or without evidence of ulceration. Of the remaining 5 one was confirmed by biopsy and the other 4 had typical ulcerative changes on sigmoidoscopy. Biopsy has been employed only relatively recently and only 10 were so investigated: all were positive. We have not included in this study 10 cases of granular proctitis.

All 25 patients were seen and examined personally 
TABLE I

Details of 25 patients

\begin{tabular}{|c|c|c|c|c|c|c|c|c|}
\hline Case no. & Sex & $\begin{array}{c}\text { Year } \\
\text { of } \\
\text { admission }\end{array}$ & $\begin{array}{l}\text { Age at onset of } \\
\text { first symptoms } \\
\qquad(y r)\end{array}$ & $\begin{array}{l}\text { Severity } \\
\text { of } \\
\text { disease }\end{array}$ & $\begin{array}{c}\text { Follow-up } \\
\text { period } \\
(y r)\end{array}$ & Result & $\begin{array}{l}\text { Type of } \\
\text { ulcerative } \\
\text { colitis } \$\end{array}$ & Surgery \\
\hline $\begin{array}{l}1 \\
2 \\
3 \\
4 \\
5 \\
6 \\
7^{*} \\
8 \\
9 \\
10 \\
11 \\
12^{*} \\
13 \\
14^{\star} \\
15 \\
16 \\
17 \\
18 \\
19 \\
20 \\
21 \\
22 \\
23 \\
24 \\
25\end{array}$ & 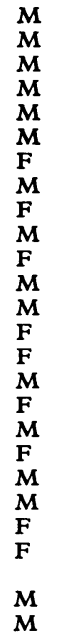 & $\begin{array}{l}1931 \\
1944 \\
1945 \\
1946 \\
1948 \\
1950 \\
1951 \\
1954 \\
1955 \\
1957 \\
1957 \\
1958 \\
1962 \\
1962 \\
1962 \\
1963 \\
1963 \\
1966 \\
1967 \\
1967 \\
1968 \\
1969 \\
1969 \\
\end{array}$ & $\begin{array}{rl}5 & 5 / 12 \\
10 & 5 / 12 \\
5 & 5 / 12 \\
10 & 11 / 12 \\
11 & 4 / 12 \\
2 & 8 / 12 \\
9 & 7 / 12 \\
10 & 11 / 12 \\
5 & 4 / 12 \\
11 & \\
4 & 5 / 12 \\
5 & \\
10 & 11 / 12 \\
6 & 4 / 12 \\
8 & 11 / 12 \\
2 & 7 / 12 \\
6 & 10 / 12 \\
9 & 4 / 12 \\
8 & 9 / 12 \\
9 & 1 / 12 \\
12 & 5 / 12 \\
8 & 1 / 12 \\
8 & 11 / 12 \\
9 & 5 / 12 \\
13 & 1 / 12\end{array}$ & $\begin{array}{l}\text { Mild } \\
\text { Moderately severe } \\
\text { Moderately severe } \\
\text { Mild } \\
\text { Moderately severe } \\
\text { Moderately severe } \\
\text { Mild } \\
\text { Mild } \\
\text { Severe } \\
\text { Moderately severe } \\
\text { Mild } \\
\text { Mild } \\
\text { Moderately severe } \\
\text { Mild } \\
\text { Severe } \\
\text { Mild } \\
\text { Moderately severe } \\
\text { Mild } \\
\text { Severe } \\
\text { Mild } \\
\text { Moderately severe } \\
\text { Moderately severe } \\
\text { Severe } \\
\text { Mild } \\
\text { Moderately severe }\end{array}$ & $\begin{array}{r}41 \\
10 \\
37 \\
26 \\
22 \\
21 \\
20 \\
18 \\
2 \\
15 \\
14 \\
14 \\
1 \\
9 \\
10 \\
9 \\
9 \\
6 \\
5 \\
5 \\
4 \\
3 \\
2 \text { wk } \\
1 \\
1\end{array}$ & $\begin{array}{l}a \\
d \\
a \text { and } w \\
a \text { and } w \\
d \\
a \text { and } w \\
a \text { and } w \\
a \text { and } w \\
d \\
a \\
a \text { and } w \\
a \text { and } w \\
d \\
a \text { and } w \\
a \\
a \text { and } w \\
a \text { and } w \\
a \text { and } w \\
a \text { and } w \\
a \text { and } w \\
a \text { and } w \\
a \\
d \\
a \text { and } w \\
a \text { and } w\end{array}$ & $\begin{array}{l}\text { CI } \\
\text { CI } \\
\text { CI } \\
\text { Single attack } \\
\text { CI } \\
\text { CI } \\
\text { CI } \\
\text { CI } \\
\text { CI } \\
\text { CI } \\
\text { Single attack } \\
\text { CI } \\
\text { CI } \\
\text { CI } \\
\text { CI } \\
\text { Single attack } \\
\text { CI } \\
\text { CI } \\
\text { CI } \\
\text { CI } \\
\text { CI } \\
\text { CI } \\
\text { Acute fulmi- } \\
\text { nating (fatal) } \\
\text { CI } \\
\text { Single attack }\end{array}$ & $\begin{array}{l}S \\
S \\
S\end{array}$ \\
\hline
\end{tabular}

$\star$ Family history positive. $† d$, died; a and $w$, alive and well. $¥ C I$, chronic intermittent.

except for 1 patient whose parents were contacted by telephone: they had returned home to Rome. Earlier information was extracted from the case records and in many cases from the recollections of their attending physicians.

The period of observation ranged from 1 to 41 years with an average of 24 years. In only 4 cases was the period of follow-up less than 5 years.

We have classified our cases clinically into mild, moderate, and severe according to the criteria of Truelove and Witts (1955). The term chronic continuous was used for those whose symptoms continued without intermission for a full year or more. Chronic intermittent was used for those in whom remissions and relapses occurred within a year (Table I).

Clinical picture. Of the 25 cases, 16 were males $(64 \%)$ and 9 females $(36 \%)$. The age range at the time of first hospital admission varied from 2 years 8 months to 13 years 1 month. The average age at the onset of first symptoms was 8 years 1 month.

A family history of ulcerative colitis was present in close relatives of 3 patients. 2 of our patients were Jewish and 1 was Italian. The symptoms in order of frequency at the first visit were as shown in Table II.

Complications (local and systemic) arising during follow-up. The most common complication which became apparent at the time of follow-up was anaemia, as $\mathrm{Hb}$ was $9.0 \mathrm{~g} / 100 \mathrm{ml}$ or less in 9 patients : all these patients showed the changes of iron deficiency anaemia. Joint complications were arthralgia in 4 and arthritis in 2 patients: the clinical picture of arthritis was the same as that seen in rheumatoid arthritis in children. 5 patients had 'pseudopolypoidal' changes in their colon on barium enema examination. Aphthous stomatitis was noted in 3 more patients. The rare complication of hepatic cirrhosis (confirmed by biopsy) was present in 2 patients, and carcinoma of rectal stump with metastases in the lumbar spine in 1 patient (Case 5). Osteoporosis was present in 2 patients; this was purely a radiological diagnosis, both patients being treated with corticosteroids at the time.

TABLE II

Symptoms at onset of disease

\begin{tabular}{l|c|c}
\hline & $\begin{array}{c}\text { No. of } \\
\text { cases }\end{array}$ & $\%$ \\
\cline { 2 - 2 } & 25 & 100 \\
Bloody diarrhoea & 22 & 88 \\
Mucus & 17 & 68 \\
Abdominal pain & 12 & 48 \\
Growth failure (ht and wt & 9 & 36 \\
<3rd centile) & 8 & 32 \\
Anorexia & 9 & 36 \\
Listlessness & 3 & 12 \\
Anaemia (Hb <9.0 g/100 ml) & 2 & 8 \\
Fever & 1 & 4 \\
Aphthous stomatitis & & \\
\hline
\end{tabular}


TABLE III

Results of surgical treatment in eight cases

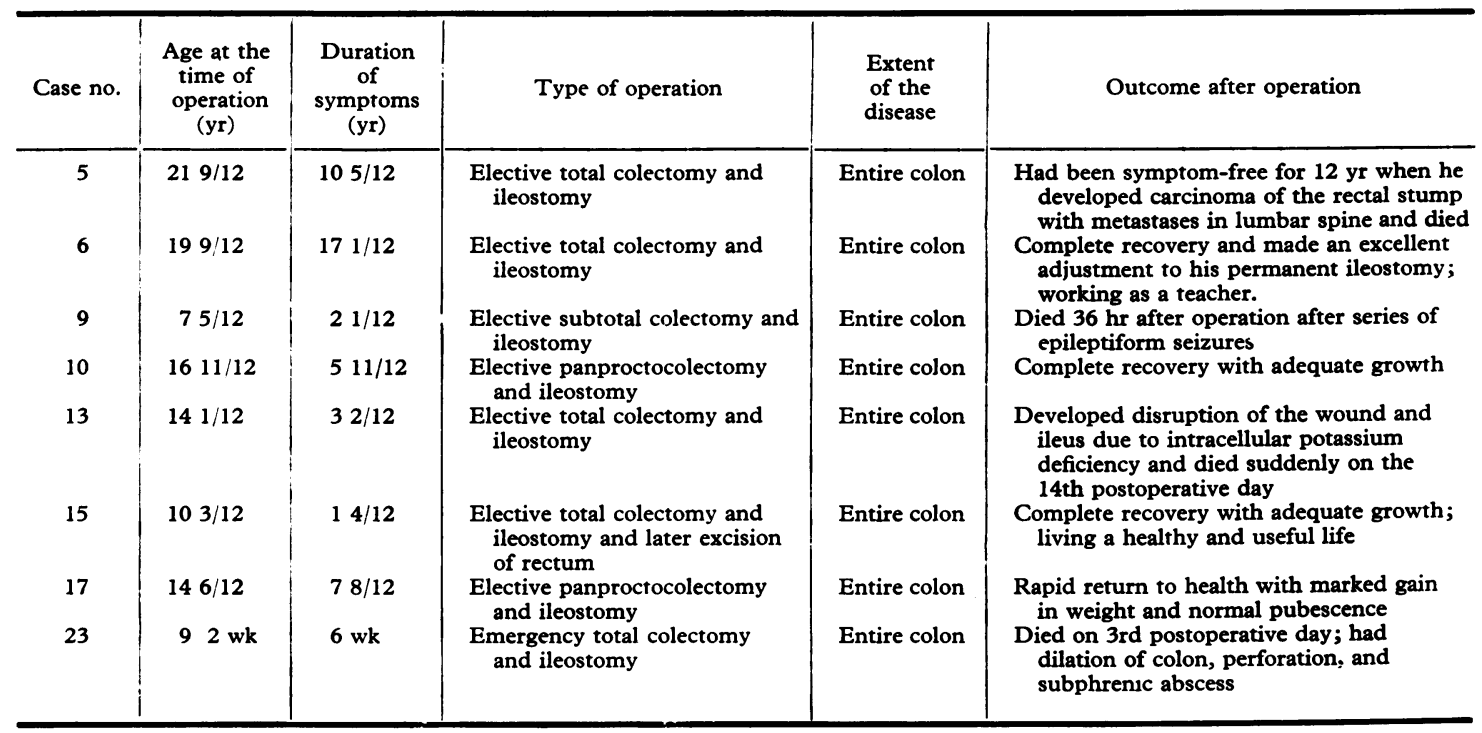

Certain other complications noted were: iritis 1 patient, nail dystrophy 1 , splintered nails 1 , erythema nodosum 1, butterfly facial rash 1 , xeroderma with patches of eczema 2 , anal fissure 2 , anal ulcer simple 1 , stricture of sigmoid 1, dilatation of colon 2, massive bleeding 1 , chronic pyelonephritis 2 , secondary hypertension 2. The use of sulphasalazine was associated with Heinz body anaemia in 1 case and nonthrombocytopenic purpura in another.

Treatment. The precortisone period (1931-1952) group comprises 7 patients $(28 \%$ ) whose illnesses began before the introduction of corticosteroids. Early management was limited to bed rest, restricted diet, antibiotic enema, opiates, sulphonamides, intravenous infusions, and blood. 2 of these 7 patients (Cases 5 and 7) were later submitted to operation.

During the cortisone period (1953-1972) a group of 10 patients was treated with a combination of lowresidue diet, sulphasalazine, and steroids. 6 patients were treated with a combination of steroids and diet, and another 2 with diet and sulphasalazine. A group of 5 patients was given only high protein and lowresidue diet. 6 patients from the cortisone period later underwent surgery. The corticosteroids were given topically and systemically.

Surgical treatment. A total of 7 patients required elective surgery as shown in Table III. Age range at the time of operation varied from 7 to $21 \frac{3}{4}$ years, and the duration of symptoms from 6 weeks to 17 years. Elective total colectomy and permanent ileostomy were performed in 4 patients (Cases 5, 6, 13, and 15) of which
1 (Case 15) had a later proctectomy. Elective subtotal colectomy and permanent ileostomy were performed in 1 patient (Case 9), and in the remaining 2 (Cases 10 and 17) panproctocolectomy. There was 1 case where emergency colectomy was required (Case 23).

The main indications for elective operations were: failure of steroid and psychiatric therapy, severe cachexia, inability to attend school, and chronic disease affecting social life.

In our series only 1 patient (Case 23) required emergency total colectomy and ileostomy for perforated ulcerative colitis. This 9-year-old girl was admitted with the history of vomiting and profuse bloody diarrhoea of 3 weeks' duration. Her barium enema showed changes of severe extensive ulcerative colitis involving the whole colon and rectum. She was originally treated with sulphasalazine and steroids. As the response to conservative treatment was poor, she had an emergency operation. The histological features were characteristic of acute fulminating ulcerative colitis. Her immediate postoperative course was uneventful, but she developed a left posterior subphrenic abscess and a left pyothorax and, despite drainage, died on the third postoperative day.

All 8 cases who had operation showed involvement of the entire colon histologically; there was no evidence of malignancy.

\section{Course and prognosis}

The subsequent course of ulcerative colitis in our series in relation to severity of first attack is shown in Table IV. 
TABLE IV

Prognosis related to clinical course

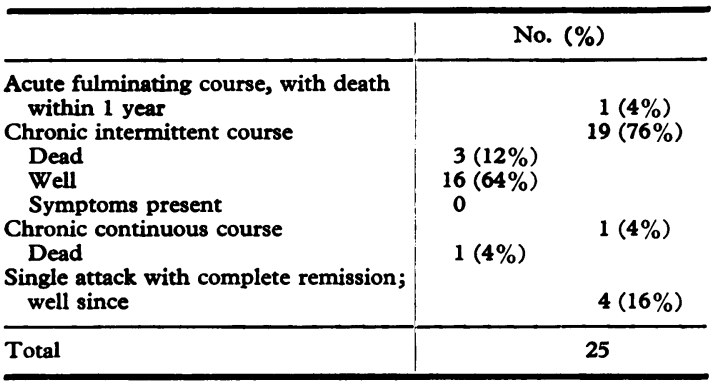

Out of 25 patients, 5 (20\%) died and the remaining 20 surviving members of our series are at present in remission, and their current status is shown in Table V. The ulcerative colitis in 3 of 5 patients who died was of the moderately severe category and severe in the other 2 . The deaths were attributable directly or indirectly to ulcerative colitis and its complications. All of the 11 patients with the mild form of the disease survived.

TABLE V

Current status of 20 surviving patients

\begin{tabular}{l|c}
\hline & No. \\
\hline $\begin{array}{c}\text { Living entirely normal life without requiring any } \\
\text { medical attention (Cases } 3,4,8,11,12,14,16,\end{array}$ & 8 \\
$\begin{array}{c}\text { and 25) } \\
\text { Living entirely normal life but attending hospital } \\
\text { for review mainly as outpatients (Cases 6,7,17, 18, } \\
19,20,21, \text { and 24) }\end{array}$ & 8 \\
$\begin{array}{c}\text { Living fairly active life but adjustments required to } \\
\text { their social activities and occupation as their } \\
\text { working capacity is reduced (Cases 1, 10, and 15) }\end{array}$ & 3 \\
$\begin{array}{c}\text { Requiring frequent medical attention, mainly for } \\
\text { complications (Case 22) }\end{array}$ & 1 \\
$\begin{array}{c}\text { Chronic invalid; patient unable to work because of } \\
\text { disability }\end{array}$ & 0 \\
\hline \begin{tabular}{l} 
Total \\
\hline
\end{tabular} & 20 \\
\hline
\end{tabular}

Four patients (16\%) had only single attacks. The period of observation for these 4 patients (Cases 4, 11, 16, and 25) varied from 1 year to 26 years, with an average of 23.5 years. All these 4 patients remained symptom-free throughout the period of follow-up.

Nineteen cases $(76 \%)$ pursued a chronic intermittent course (Table IV) with periods of complete freedom from symptoms interspersed with attacks of the disease. 16 of these $(64 \%)$ are at present in remission, while 3 (Cases 2, 5, and 9) died. The ulcerative colitis of patients 2 and 5 was moderately severe and of Case 9, severe in type. Case 2 was from the precortisone period and he died at the age of 20 years due to progressive hepatic cirrhosis and portal hypertension 9 years after the diagnosis of ulcerative colitis. Case 5, also from the precortisone period, died at the age of 34 years, 22 years after diagnosis. He had elective total colectomy and permanent ileostomy at the age of 21 years 9 months. This is the only case in our series of 25 patients who developed carcinoma-carcinoma of the rectal stump with metastases in the lumbar spine 12 years after surgery. Case 9 (chronic intermittent-severe) died 36 hours after elective subtotal colectomy and ileostomy after a series of epileptiform seizures. The seizures were thought to be related to the heavy steroid dosage.

There was only 1 case of chronic continuous type (Case 13); this patient died suddenly on the 14th postoperative day after elective total colectomy and ileostomy.

Case 23, the only case of acute fulminating type (severe), died on the third postoperative day after emergency colectomy and ileostomy.

There were 5 patients (Cases 5, 6, 10, 15, and 17) who survived operative therapy. All these 5 patients had a rapid weight gain after the removal of their diseased colon. Case 17, a female patient whose puberty was delayed before surgery, had a normal pubescence after operation. The current status of the 20 surviving members of our series is shown in Table V. There are 8 patients (Cases $3,4,8,11,12,14,16$, and 25) who are living entirely normal lives without requiring any medical attention. This group includes 4 patients who have had only a single attack of the disease.

There is another group of 8 patients, all chronic intermittent (Cases 6, 7, 17, 18, 19, 20, 21, and 24), who are also living entirely normal lives but who attend the hospital for review. This group includes 2 patients (Cases 6 and 17) who had elective surgery.

Three patients (Cases 1, 10, and 15) are living fairly active lives, but they have had to make some adjustment to their social activities as their working capacity is reduced.

The ulcerative colitis of Case 22 was quiescent at the time of writing, but this patient attends hospital frequently because of chronic pyelonephritis and secondary hypertension.

\section{Discussion}

The true incidence of ulcerative colitis in children is unknown. The disease may occur in infancy, but is more common in children of school age. Avery and Harkness (1964) reported the occurrence of a typical though transient clinical picture of ulcerative colitis in a newborn infant whose mother had the disease. One of our female patients 
(Case 15), who had elective colectomy and ileostomy in 1963, recently gave birth to a normal infant. In the experience of De Dombal et al. (1965) most pregnant women with ulcerative colitis have normal infants.

Of our patients $12 \%$ have a family history of ulcerative colitis, and it has been reported that between 5 and $10 \%$ of patients have a positive family history, about 10 times the figure which would be expected by chance (Kirsner and Spencer, 1963; Goligher et al., 1968).

Lagercrantz (1949) found a greater incidence in boys than in girls. Our series also shows a slight predominance of males (64\%), but Platt et al. (1960) found no sex distinction in their series.

Two of our patients were Jewish children, and other authors (Paulley, 1950; Platt et al., 1960) have reported a high incidence of ulcerative colitis in Jewish children. Paulley (1950) related the high incidence to the greater emotional disturbance in parents, especially maternal dominance and possessiveness in Jewish families.

Ulcerative colitis may pursue various forms, but the most common type is the chronic intermittent form. In our series, $76 \%$ were of the chronic intermittent type; Lagercrantz (1955) and Platt et al. (1960) had a similar experience as the incidence of this type of ulcerative colitis in their series was $78 \%$ and $58 \%$, respectively. We had only 1 patient of the chronic continuous type in our series; De Dombal (1971) reports that this type seems to have become rare recently, probably because of treatment.

The prognosis of the acute fulminating type has been reported to be exceedingly poor (Almy, 1961; Almy and Lewis, 1963). We had a similar experience, as our only case of this type (Case 23) died on the third postoperative day after emergency colectomy and ileostomy.

Extracolonic manifestations are more common in children than in adults (Broberger and Lagercrantz, 1966), and in our series, $76 \%$ of children showed these. The hepatic complications are not related to the extent or the severity of ulcerative colitis but in some series have affected the prognosis (Ihre, 1963; Lagercrantz, 1949). We had a similar experience as two of our patients had hepatic complications: one (Case 2) died of hepatic cirrhosis and portal hypertension, and the other patient (Case 10) had to change his job because of progressive hepatic cirrhosis.

The local complications are uncommon in childhood, but it is the late complication of colonic or rectal cancer that is the most serious complication. Various authors (Bargen and Gage, 1960; Edwards and Truelove, 1963; Devroede et al., 1971) have reported the incidence of carcinoma to be greater when the colitis starts in childhood. The reported incidence in several series including our own is shown in Table VI.

Devroede et al. (1971) reported that the risk of cancer is low in the first 10 years of the disease but thereafter this complication develops in roughly $20 \%$ of the exposed children in each successive decade. In 11 patients of our series the period of observation varied from 10 to 41 years, yet only 1 patient developed carcinoma. This was of the postoperative rectal stump and doubtless could have been prevented by more radical surgery.

It seems, therefore, that the case has been made for panproctocolectomy in acute fulminating ulcerative colitis, and in chronic intermittent ulcerative colitis when this has proved resistant to medical treatment and the state of the colon leads to fear of perforation or the general state of the child causes severe growth and developmental retardation and continuing social disability. The undoubted hazards of surgery must be weighed against the advantages, but so also must the risk of delay. The extension of panproctocolectomy to those in whom the disease is quiescent as a means not of treatment but of prophylaxis against later carcinomatous change seems to require more justification than the literature and our own

TABLE VI

Incidence of carcinoma among children with ulcerative colitis

\begin{tabular}{|c|c|c|c|c|c|}
\hline Authors & $\begin{array}{l}\text { No. of cases of } \\
\text { ulcerative colitis } \\
\text { reported }\end{array}$ & $\begin{array}{l}\text { No. of cases of } \\
\text { carcinoma } \\
\text { (and \%) }\end{array}$ & $\begin{array}{c}\text { Age range at } \\
\text { onset of } \\
\text { ulcerative colitis } \\
\text { (and average) (yr) }\end{array}$ & $\begin{array}{c}\text { Range of } \\
\text { duration of } \\
\text { ulcerative colitis } \\
\text { (and average) }(y r)\end{array}$ & $\begin{array}{l}\text { Average period } \\
\text { of follow-up } \\
(y r)\end{array}$ \\
\hline $\begin{array}{l}\text { Gleckler and Brown (1950) } \\
\text { Lagercrantz (1955) } \\
\text { Platt et al. (1960) } \\
\text { Patterson, Castiglioni, and Sampson (1971) } \\
\text { Present series }\end{array}$ & $\begin{array}{r}316 \\
137 \\
62 \\
43 \\
25\end{array}$ & $\begin{array}{r}12(3 \cdot 8) \\
6(4 \cdot 4) \\
2(3 \cdot 2) \\
2(4 \cdot 6) \\
1(4 \cdot 0)\end{array}$ & $\begin{array}{l}13-45(28) \\
2-15(11) \\
5-8(66 / 12) \\
12-16(14) \\
114 / 12\end{array}$ & $\begin{array}{l}6-31(16) \\
5-25(10) \\
15-21(18) \\
11-17(14) \\
22\end{array}$ & $\begin{array}{l}36 / 12 \\
26 / 12 \\
176 / 12 \\
14 \\
22\end{array}$ \\
\hline
\end{tabular}


experience provides. We hope that the next 41 years will provide more effective medical treatment and so avoid the mutilating surgery of a permanent ileostomy.

We thank our medical and surgical colleagues for access to their records, and also the patients who so willingly came to see us after so many years of freedom from disease.

\section{REFERENCES}

Almy, T. P. (1961). Ulcerative colitis. Gastroenterology, 41, 391. Almy, T. P., and Lewis, C. M. (1963). Ulcerative colitis: report of progress, based upon the recent literature. Gastroenterology, 45, 515.

Avery, G. B., and Harkness, M. (1964). Bloody diarrhoea in the newborn infant of a mother with ulcerative colitis. Pediatrics, 34, 875.

Bargen, J. A., and Gage, R. P. (1960). Carcinoma and ulcerative colitis: prognosis. Gastroenterology, 39, 385.

Broberger, O., and Lagercrantz, R. (1966). Ulcerative colitis in childhood and adolescence. In Advances in Pediatrics, Vol. 14, p. 9. Ed. by S. Z. Levine. Year Book Medical Publishers, Chicago.

De Dombal, F. T. (1971). Ulcerative colitis. British Medical fournal, 1, 649.

De Dombal, F. T., Watts, J. M., Watkinson, G., and Goligher, J. C. (1965). Ulcerative colitis and pregnancy. Lancet, 2, 599.

Devroede, G. J., Taylor, W. F., Sauer, W. G., Jackman, R. J., and Stickler, G. B. (1971). Cancer risk and life expectancy of children with ulcerative colitis. New England fournal of Medicine, 285, 17
Edwards, F. C., and Truelove, S. C. (1963). The course and prognosis of ulcerative colitis. Gut, 4, 299.

Gleckler, W. J., and Brown, C. H. (1950). Carcinoma of the colon complicating chronic ulcerative colitis. Gastroenterology, 14, 455.

Goligher, J. C., De Dombal, F. T., Watts, J. M., and Watkinson, G. (1968). Ulcerative Colitis, p. 60. Baillière, London.

Hanley, P. H., and Ray, J. E. (1968). Ulcerative colitis in children. Southern Medical fournal, 61, 1231.

Ihre, B. J. E. (1963). Ulcerative colitis from a surgical point of view. Acta Chirurgica Scandinavica, 125, 453.

Kirsner, J. B., and Spencer, J. A. (1963). Family occurrences of ulcerative colitis, regional enteritis, and ileocolitis. Annals of Internal Medicine, 59, 133.

Lagercrantz, R. (1949). Ulcerative colitis in children. Acta Paediatrica, 37, Suppl. 75, 89.

Lagercrantz, R. (1955). Follow-up investigation of children with ulcerative colitis, with special reference to indications for surgical therapy. Acta Paediatrica, 44, 302.

Patterson, M., Castiglioni, L., and Sampson, L. (1971). Chronic ulcerative colitis beginning in children and teenagers. American fournal of Digestive Diseases, 16, 289.

Paulley, J. W. (1950). Ulcerative colitis: a study of 173 cases. Gastroenterology, 16, 566.

Platt, J. W., Schlesinger, B. E., and Benson, P. F. (1960). Ulcerative colitis in childhood: a study of its natural history. Quarterly fournal of Medicine, 29, 257.

Truelove, S. C., and Witts, L. J. (1955). Cortisone in ulcerative colitis. British Medical fournal, 2, 1041.

Correspondence to Dr. R. A. Shanks, Royal Hospital for Sick Children, Yorkhill, Glasgow G3 8SJ. 